\title{
Students' Computer Literacy: Covariate For Assessing The Efficacy Of Computer Assisted Learning Tools
}

\author{
Ronald R. Tidd (E-mail: Ron@rrtidd.com), Central Washington University
} Richard Fenzl, Baldwinsville, NY

\begin{abstract}
The purpose of this paper is to focus attention on the need to more rigorously measure computerspecific student characteristics when assessing the efficacy of computer assisted learning tools and benchmarking a curriculum's impact. It accomplishes this by first modeling learning outcomes assessment, identifying appropriate instruments, and discussing the absence of such measures in accounting education research. Then, the measurement process employed by the authors is discussed. The unsurprising results reveal statistically significant differences in computer anxiety and perceptions of computer skills across the student population. The significant implication is that heterogeneity must be controlled for when assessing resource-intensive computer assisted learning methods: Failure to do so will impair educators' ability to determine the efficacy of computer assisted learning and the curriculum's contribution to students' development.
\end{abstract}

\section{Introduction}

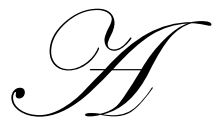

cademicians are increasingly reminded that they will be held accountable for graduating students who meet societal needs. The accounting profession, for example, has identified its need for graduates who possess a foundation comprising core competencies (American Institute of Certified Public Accountants, 2000) and skills, knowledge, and professional orientation (Accounting Education Change Commission, 1990; Arthur Andersen et al, 1989; Siegel and Sorensen, 1994). If accounting educators believe these goals to be important, then they must design and implement mechanisms to assess the accounting curriculum's ability to help students achieve them.

This becomes more important as computer technology assumes an expanding role in the learning process (Ash, 2000). Such technology requires significant resources, although there is no compelling evidence that it is more effective or efficient in achieving the desired learning outcomes (Russell, 2000; Williams et al 1988, pp. 110-111). This is not surprising since the technology has been used primarily to automate traditional pedagogy. Responses to calls to use computer technology to reengineer the learning process (CAUSE, 1993; Dede, 1992; Stahlke, 1996; Twigg and Miloff, 1998) are relatively recent and there has not been sufficient time to assess the technology's impact in a reengineering role.

Regardless of the method of deployment or the research issue, technology's impact on learning outcomes will be affected by student characteristics (Bonner, 1999; Boyce, 1999; Bryant and Hutton, 2000), including computer-related skills (Evans, 1998), knowledge, and anxiety. Therefore, it is necessary to define and measure technology-specific student characteristics, although their multidimensional nature suggests the difficulty of defining and measuring appropriate constructs. Several researchers have defined and measured components of computer literacy (Harrison and Rainer, 1992; Heinssen et al, 1987; Loyd and Gressard, 1984; Marakas et al, 1998; Mawhinney et al, 1993; Murphy et al, 1989; Nickell and Pinto, 1986), as the construct is generally referred to, but those measures have been substantially ignored in research on the efficacy of computer assisted learning (CAL).

Readers with comments or questions are encouraged to contact the authors via email. 
The purpose of this paper is to focus attention on the need to more rigorously measure computer-specific student characteristics when assessing the efficacy of computer assisted learning tools and benchmarking a curriculum's impact. The next section reviews the research in the outcomes assessment, computer literacy, and accounting curriculum literature to develop the theoretical foundation for measuring technology-specific student characteristics. That foundation is operationalized with a linear model that integrates the three bodies of literature. The next section discusses the measurement process used with undergraduate and graduate students in the school of management at a private university. The results of that process suggest statistically significant differences across the student population on computer-specific student characteristics that will influence i) the efficacy of computer-assisted learning and ii) the ability to measure the curriculum's contribution to student learning. The paper ends with a discussion of the results and recommendations for future research.

\section{Literature Review}

The foundations for this paper draw upon three bodies of research. The learning assessments literature provides a fruitful model for measuring computer assisted learning outcomes, while the computer literacy literature examines some of the relevant student characteristics for measuring outcomes when computers are a component of the learning environment. The literature on the efficacy of CAL in the accounting curriculum illustrates the extent to which student characteristics actually have been considered by empirical researchers in that curriculum.

\section{Assessing Learning Outcomes}

Learning outcomes can be modeled as a function of conditions that are internal and external to the learner (Gagné et al, 1992, p. 9), or in other words, as characteristics of the learner and the learning environment (Teaching and Curriculum Section, American Accounting Association 1993, p. 3). A detailed discussion of the components of the model is outside the purview of this paper. However, some discussion is useful, as the model provides a fruitful structure for analyzing the issue of interest.

Generally, the dependent variable is some learning outcome. It is operationalized with a test of student performance that measures learned capabilities that reflect the learning objectives Gagné et al $(1992$, p. 9) provide a useful taxonomy of learned capabilities (Table 1). The independent variables then include the two explanatory variables (learner and environmental characteristics). They must be decomposed, as Table 2 illustrates.

\begin{tabular}{ll}
\hline \hline Classification & \multicolumn{1}{c}{ Table 1: Taxonomy of Learned Capabilities } \\
\hline \hline Intellectual Skills & $\begin{array}{l}\text { Learner interacts with the environment in terms of symbols or conceptualizations; involves } \\
\text { learning how to do something intellectual (procedural knowledge). }\end{array}$ \\
Cognitive Strategies & $\begin{array}{l}\text { Learner selects and modifies his/her way of attending, learning, remembering, and think- } \\
\text { ing based on an internal control process }\end{array}$ \\
Verbal Information & $\begin{array}{l}\text { Learner stores verbal knowledge as networks of propositions that conform to the rules of } \\
\text { language. (declarative knowledge) }\end{array}$ \\
Motor Skills & $\begin{array}{l}\text { Learner has capabilities that underlie performances whose outcomes are reflected in the } \\
\text { rapidity, accuracy, force, or smoothness of bodily movement }\end{array}$ \\
Attitudes & $\begin{array}{l}\text { Learner's internal state that affects his/her choice of personal action toward some object, } \\
\text { person, or event. }\end{array}$ \\
\hline \hline
\end{tabular}

There are two notable points regarding this typical formulation. First, the extant research employs measures 
of student characteristics that have explanatory power in research on the efficacy of traditional pedagogy. Those measures include demographic (age and gender) and cognitive characteristics (grades). Those measures do not include technology-specific characteristics such as attitudes and skills (keyboards and software) which, theoretically, will affect CAL outcomes.

\begin{tabular}{ll}
\hline \hline \multicolumn{1}{c}{ Table 2: Components of Explanatory Variables in Outcomes Assessment } \\
\hline \hline Student characteristics & $\underline{\text { Environmental characteristics }}$ \\
Prior Learning & Learning and teaching strategies \\
Demographic Characteristics & Curricular structure and integration \\
Cognitive Characteristics & Faculty attitudes and teaching behaviors \\
Student Educational Goals & Organizational practices \\
Affective Characteristics & Use of emerging technologies \\
\hline \hline
\end{tabular}

Second, the research issue should determine how the measures of student characteristics are used in the assessments model (Stone et al, 1996). The literature includes several experimental designs (Williams et al 1988, pp. 99 - 130; Thompson et al, 1993, pp. 39 - 52), including those that:

- $\quad$ Compare learning outcomes from alternative media

- $\quad$ Distinguish learning outcomes based on student characteristics, with the technology held constant

- $\quad$ Assess the impact of technology on students' attitudes toward learning

- $\quad$ Assess the cost-effectiveness of CAL

These studies demonstrate that a measure of a student characteristic may be used as the dependent variable, rather than as an independent variable. For example, when comparing instructional media, the dependent variable would be a measure of knowledge, the independent treatment variable would be the method used to deliver course content (computer or lecture), and the independent control variables would include student characteristics. When assessing the impact of technology on the attitudes of students with different abilities, the dependent variable would be a measure of attitude, while the independent treatment variable would be a measure of ability, and the independent control variables would include student characteristics other than ability. Clearly, rigorous research must integrate measures of student characteristics, whether they are used as dependent or independent variables.

\section{Assessing Computer Literacy}

Computer literacy is a broadly defined construct that may transcend all five of the student characteristics listed in Table 2. This complicates the development of a unified measure that would have broad application to a variety of issues. Consequently, individual researchers have operationalized the construct with measures that were appropriate for their more narrowly defined research issues. For example:

- $\quad$ Computer Attitude Scale (CAS)- developed to measure positive and negative attitudes towards computers (Loyd and Gressard, 1984)

- $\quad$ Computer Anxiety Rating Scale (CARS)- designed to measure the degree to which interaction with computers (actual or anticipated) would affect individual performance (Heinssen, Glass, and Knight, 1987)

- $\quad$ Computer Self-Efficacy Scale (CSES) - developed to measure individual's perceptions of capabilities regarding specific computer-related knowledge and skills (Murphy et al, 1989). 
These scales are mentioned because 1) they suggest the multidimensional nature of computer literacy and 2) their psychometric properties have been established as acceptable (Harrison and Rainer, 1992; Loyd and Gressard, 1984; Nickell and Pinto, 1986).

Also, it is worth noting that some studies found statistically significant differences in scores based on gender and age: men (and young people) have more positive attitudes (Nickell and Pinto, 1986), higher self-efficacy beliefs (Murphy et al, 1989), and less computer anxiety (Liu et al, 1992). In contrast, Heinssen et al (1987) found no gender based differences in computer anxiety, when the subject pool was younger and more homogeneous than that used by Liu et al. Thus, the evidence suggests that these measures may be correlated with student characteristics such as age and gender.

These measures have not been widely used as covariates in outcomes assessment. This is explained, in part, by their issue-specific nature, which diminishes their generalizability. In addition, the technology has evolved faster than some components of the scales: Some questions refer to mainframe computing rather than distributed computing. The measures also are criticized for focusing on computer literacy when the emphasis should be on computing literacy- computer use that enriches one's professional and personal life (Amini, 1994).

\section{Assessing CAL in the Accounting Curriculum}

Accounting researchers have not ignored student characteristics when assessing the impact of computers in the accounting curriculum. However, only Borthick and Clark (1986, 1987a), in the recent research considers more than a subset of this component of the assessment model and some measure related to computer literacy.

The conclusions provide no conclusive evidence about the efficacy of computer-assisted learning:

- Weaker students demonstrated enhanced performance, while better students demonstrated equal performance vis-à-vis students with similar characteristics who were not taught with computers (Fetters et al, 1986).

- $\quad$ Subjects reported a decreased interest in CAL after the experiment and demonstrated no enhanced learning (Borthick and Clark, 1986).

- $\quad$ Subjects demonstrated a statistically significant improvement in writing (Borthick and Clark, 1987a).

- $\quad$ Subjects using computers demonstrated no statistically significant improvement in performance vis-à-vis subjects not using computers, after student characteristics unrelated to the technology were accounted for (Oglesbee et al, 1988).

- $\quad$ Subjects using an expert system to study leases made fewer errors when classifying leases and reported that the learning task was less useful than subjects who did not use an expert system (Böer and Livnat, 1990).

- $\quad$ Students who studied with computers performed better than students who did not, even after controlling for non-treatment differences (Kachelmeier et al, 1992).

- $\quad$ Subjects who used CAL to supplant lectures performed as well on examinations but reported less interest in studying accounting than subjects who used lectures; Subjects who used CAL to support lectures performed as well on examinations than those who used lectures only (McInnes et al, 1995).

- $\quad$ Subjects who prefer graphical representations of information demonstrate higher recall from multimedia presentations than do those who prefer verbal representations. Regardless of learning preferences, subjects report positive attitudes towards multimedia presentations and the presenter (Butler and Mautz, 1996).

- Holistic CAL that is sensitive to learning preferences provides a satisfying learning experience and in the absence of a control group that does not use CAL, student self-efficacy and attitudes towards multimedia learning are enhanced (Evans, 1998).

- $\quad$ Subjects had a more satisfying CAL experience once administrative problems were resolved (Gujarathi and McQuade, 1998).

- $\quad$ Subjects who used electronic tutorials and team learning in a tax course performed better on assessment exercises and reported higher course satisfaction than those who did not use CAL (Parker and Cunningham, 1998). 
Borthick and Clark $(1986,1987 \mathrm{a})$ report nothing to suggest that the psychometric properties of their measure of computer literacy were evaluated.

Oglesbee et al (1988) found a statistically significant difference in student performance, before using selection differences in their analyses, suggesting the importance of proper specification in the statistical model. The bias associated with omitted variables is especially important in this domain, since, as noted, the research suggests that computer literacy (omitted) is correlated with gender and age (usually included).

\section{Integrating the Literature}

It is informative to operationalize the outcomes assessment function with a linear model of the form $\mathbf{y}_{\mathrm{i}}=\alpha+\mathbf{X}_{\mathrm{i}} \boldsymbol{\beta}^{\mathrm{s}}+\mathbf{Z}_{\mathrm{i}} \boldsymbol{\beta}^{\mathrm{e}}+\varepsilon_{\mathrm{i}}$

where $\mathbf{y}_{\mathbf{i}}$ measures the performance of student $\mathrm{i}$, on some task. The design matrix is partitioned into two components, the row vectors $\mathbf{X}_{\mathbf{i}}$ and $\mathbf{Z}_{\mathbf{i}}$, which consist of the measures of student i's personal and environmental characteristics, respectively. The column vectors $\boldsymbol{\beta}^{\mathrm{s}}$ and $\boldsymbol{\beta}^{\mathrm{e}}$ thus include the weights associated with those characteristics and $\boldsymbol{\alpha}$ measures an intercept term. These elements are common for all students, but the error term, $\boldsymbol{\varepsilon}_{\mathbf{i}}$, applies to each student.

With an appropriately specified measure of the desired outcome, this model could be used to assess the efficacy of computer assisted learning in improving students' knowledge, skills, or attitudes. Thus, the measures discussed in this paper would be appropriate measures of covariates $\left(\mathbf{X}_{\mathbf{i}}\right)$ or learning outcomes $\left(\mathbf{y}_{\mathbf{i}}\right)$, depending on the learning objective. (The measures would be covariates when the learning goal is to help students improve intellectual skills, but outcomes when the learning goal was to improve student perceptions about and attitudes towards computers.)

If the theory and its operationalization are correct, then the statistical model will not be properly specified if relevant student characteristics are omitted as covariates for an environment with a given computerized learning tool. The omission always produces biased variance-covariance estimators and inaccurate inferences. Misspecification is especially problematic when the omitted variables are correlated with included variables, which the research suggests is the case; biased estimators of the elements in $\boldsymbol{\beta}^{\mathbf{s}}$ and $\boldsymbol{\beta}^{\mathbf{e}}$ result.

\section{Implementation}

The primary objective of this research is to focus research attention on the biased estimators problem and suggest a solution. If the measures detect statistically significant computer-specific differences in the student population, then they should be used as covariates for experiments that rigorously assess the contribution of CAL to the learning process. A secondary purpose of this research is to suggest the value of these measures in curriculum design and assessment. By measuring students' computer skills and attitudes at key times in their academic career, the measures provide guidance for curriculum design and remedial training, and quantifying the curriculum's impact on student development. The later is especially important to educators who are being held accountable for their efforts.

\section{Instrument}

Data were gathered with a survey instrument comprising two sections (Appendices 2 and 3). ${ }^{1}$ The first section requested demographic data and detailed information about personal experience and skill with different computer platforms. This information was not anonymous, as it was necessary to identify students who needed additional guidance with computer applications. The second section was anonymous and presented fifty-two questions with Likert-style scales from the Computer Self-Efficacy Scale and the Computer Anxiety Rating Scale. To keep the instrument at a reasonable length, the Computer Attitude Scale was not used. 


\section{Subjects}

The instrument was administered to students in the school of management at the graduate and undergraduate levels (Table 4). The former were enrolled in either a master's program in accounting or an MBA program; the latter were enrolled in either a business survey and skills course for freshmen, an introductory information systems course, an advanced tax course, or an upper-level course in entrepreneurship. (Although each respondent's major was identified, the data is partitioned by accounting and non-accounting majors for this analysis.) Four-hundred and thirty-three students took the original survey during the 1994/1995 academic year.

\begin{tabular}{llll}
\hline \hline \multicolumn{1}{c}{ Table 4- Population Profile (Summary Statistics) } \\
\hline \hline Population & \multicolumn{1}{c}{ Mean Response (Std. Dev. ) } \\
Gumbers / Percentage & $\underline{\text { CSES }}$ & $\underline{\text { CARS }}$ \\
Gender & & $118.8(23)$ & $37.3(11.1)$ \\
Female & $163 / 38 \%$ & $123.2(26.3)$ & $34.7(10.0)$ \\
Male & & \\
Grade & $270 / 62 \%$ & $119.8(22.4)$ & $35.8(10.2)$ \\
Freshman & & $119.3(26.7)$ & $35.9(11.0)$ \\
Sophomore & $155 / 36 \%$ & $117.4(23.6)$ & $37.9(11.2)$ \\
Junior & $103 / 24 \%$ & $124.7(24.9)$ & $36.1(9.9)$ \\
Senior & $64 / 15 \%$ & $130.5(28.2)$ & $32.9(10.0)$ \\
Graduate & $36 / 8 \%$ & $121.4(24.0$ & $34.2(10.4)$ \\
Degree major & $75 / 17 \%$ & $121.6(25.4)$ & $36.0(10.6)$ \\
Accounting & $77 / 18 \%$ & & \\
Non-accounting & $356 / 82 \%$ & & \\
& &
\end{tabular}

\section{Results \& Discussion}

A $5 \times 2 \times 2$ (grade $\mathrm{x}$ gender $\mathrm{x}$ major) analysis of variance was prepared for both dependent variables CSES (efficacy) and CARS (anxiety). The main effects and all possible interaction effects were tested. As the F values in Table 5 show, there were different results for each dependent variable. ${ }^{2}$

Only grade had a statistically significant effect on self-efficacy. It was a positive effect, indicating that personal perceptions of efficacy increase with age, at least within the age range of the tested population. In addition, the LSD $t$ tests for linear comparisons showed statistically significant differences between graduate students and students in every other grade classification except seniors, at the. 05 level. Since the graduate students have work experience, this suggests that the grade variable might be a surrogate measure for computer experience. This conclusion is further supported by the "trend by grade" in the means listed in Table 4 . While there were no statistically significant differences between the undergraduate students, there may be practical significance to the score for the junior class, which was the lowest average. The freshmen and sophomore classes were the first two classes to receive more intensive computer training in a revised freshman course; the seniors would have gained significant exposure in their course work. Obviously the scores increase with computer usage, but it is not possible to determine whether this is occurring because of improved training or higher student experience levels at matriculation.

Gender had a statistically significant main effect on anxiety, while grade and major had a statistically significant interaction effect. Females reported higher anxiety, which is consistent with a broad body of research in a variety of disciplines including technology, math, and science. However, it also adds more fuel to a fire that may be extinguished once the more technologically liberated $\mathrm{X}$ generation is fully integrated into the system. Table 6 provides insights into the interaction effect. The freshman, sophomore, and junior accounting students reported lower anxiety levels than the non-accounting majors in those grades. This outcome is consistent with the perspective that accounting students share personality characteristics (or perhaps curriculum experiences) that make them more receptive to technology (Landry et al 1986). The outcome is reversed for the senior and graduate students, but the sample size for 
accounting students is much to small for statistical inference.

\begin{tabular}{lll}
\hline \hline \multicolumn{1}{c}{ Source } & Table 5- ANOVA F Values / p values \\
\hline Grade & $\underline{\text { CSES }}$ & $\underline{\text { CARS }}$ \\
Gender & $3.36 / .010$ & $2.08 / .0829$ \\
Major & $2.61 / .1069$ & $6.46 / .0114$ \\
Grade x Gender & $.28 / .5951$ & $3.34 / .0683$ \\
Grade x Major & $.84 / .5005$ & $.30 / .8776$ \\
Gender x Major & $.39 / .8188$ & $2.89 / .0220$ \\
Grade x Gender x Major & $.06 / .8023$ & $2.41 / .1210$ \\
& $.61 / .6574$ & $.39 / .8158$ \\
\hline \hline
\end{tabular}

Gender had a statistically significant main effect on anxiety, while grade and major had a statistically significant interaction effect. Females reported higher anxiety, which is consistent with a broad body of research in a variety of disciplines including technology, math, and science. However, it also adds more fuel to a fire that may be extinguished once the more technologically liberated X generation is fully integrated into the system. Table 6 provides insights into the interaction effect. The freshman, sophomore, and junior accounting students reported lower anxiety levels than the non-accounting majors in those grades. This outcome is consistent with the perspective that accounting students share personality characteristics (or perhaps curriculum experiences) that make them more receptive to technology (Landry et al 1986). The outcome is reversed for the senior and graduate students, but the sample size for accounting students is much to small for statistical inference.

\begin{tabular}{lllll}
\hline \hline & \multicolumn{2}{c}{ Table 6- Interaction in CARS: Grade and Major } & \\
\hline \hline Grade & Major & N & Mean & SD \\
& & & 35.8 & 10.2 \\
Freshman & Non-accounting & 130 & 35.6 & 10.1 \\
& Accounting & 25 & 36.6 & 10.9 \\
Sophomore & Non-accounting & 78 & 33.7 & 11.3 \\
& Accounting & 25 & 40.8 & 10.2 \\
Junior & Non-accounting & 46 & 30.6 & 10.5 \\
& Accounting & 18 & 35.5 & 4.7 \\
Senior & Non-accounting & 32 & 40.5 & 10.0 \\
& Accounting & 4 & 32.6 & 8.1 \\
Graduate & Non-accounting & 70 & 38.0 & \\
& Accounting & 5 & & \\
\hline \hline
\end{tabular}

In addition, the junior class distinguished itself once again. The LSD t test indicated a statistically significant difference in the reported anxiety of the members of that class and that of graduate students, at the. 05 level. Furthermore, that class had the highest average anxiety level and the greatest standard deviation (Table 4). Regardless of the statistical significance, the practical significance of the results on both measures is that the junior class has a problem with computer technology.

\section{Conclusions and Future Research}

It is not possible to determine whether the absence of a measure of computer literacy would have affected the conclusions in the experiments cited in the literature review. It is also not possible to generalize the results of this study beyond the school of management in which the tests were conducted. However, these results contribute to a growing body of research that supports the conclusion that the student population is not homogeneous with respect to characteristics that affect academic performance including the use of computer-based learning tasks. 
Many of the differences in these student characteristics can not be "corrected," and they certainly can not be ignored as academia moves to individualized education. Those charged with designing curriculum must consider them differences and implement the appropriate measures as part of the curriculum design. In the current wave of curriculum revision and accountability, designers must be aware that instruments exist that can help them identify the extent and nature of the differences, establish baseline measures, and assess the success of their programs.

Those interested in researching the efficacy of computer based learning and teaching methods must also consider the role that the student characteristics play in the outcome assessment model. It is probably not possible to find a perfect instrument for measuring the relevant characteristics in the constantly evolving computing environment (Marakas et al, 1998). But that does not mean that accounting researchers can continue to ignore those characteristics in tests of computerized tools. To paraphrase Borthick and Clark (1987b, p. 188): Without properly designed research, educators will never know the extent of learning effects.

\section{References}

1. Accounting Education Change Commission. (1990). Objectives of Education for Accountants: Position Statement No. One. Torrance, CA: American Accounting Association.

2. American Institute of Certified Public Accountants (2000). AICPA Core Competency Framework for Entry into the Accounting Profession. http://www.aicpa.org/edu/corecomp.htm. (Accessed March 10, 2001.)

3. Amini, M. (1994). Assessing computing literacy of business students in a regional university: Prospects for the 90s. Journal of Information Systems Education, 5, 23-30.

4. Arthur Andersen \& Co., Arthur Young, Coopers \& Lybrand, Deloitte Haskins \& Sells, Ernst \& Whinney, Peat Marwick Main \& Co., Price Waterhouse, \& Touche Ross. (1989). Perspectives on Education: Capabilities for Success in the Accounting Profession.

5. Ash, C. (2000). Towards a new cost-aware evaluation framework. Educational Technology and Society, 3(4), 126-131.

6. Böer, G., \& Livnat, J. (1990). Using expert systems to teach complex accounting issues. Issues in Accounting Education, 5(1), 108-119.

7. Bonner, S. (1999). Choosing teaching methods based on learning objectives: An integrative framework. Issues in Accounting Education, 14 (1), 11-39.

8. Borthick, A., \& Clark, R. (1987a). Improving accounting majors' writing quality: The role of language analysis in attention directing. Issues in Accounting Education, 2 (1), 13-27.

9. Borthick, A., \& Clark, R. (1987b). Research on computing in accounting education: Opportunities and impediments. Issues in Accounting Education, 2 (2), 173-192.

10. Borthick, A., \& Clark, R. (1986). The role of productive thinking in affecting student learning with microcomputers in accounting education. Accounting Review, January, 143-157.

11. Boyce, G. (1999). Computer-assisted teaching and learning in accounting: Pedagogy or product? Journal of Accounting Education, 17, 191-220.

12. Busta, B., \& Kimmel, P. (1993). Instructional game: Exploring the impact of information on the stock market. Issues in Accounting Education, 82, 378-390.

13. Butler, J., \& Mautz, R. (1996). Multimedia presentations and learning: A laboratory experiment. Issues in Accounting Education, 11(2), 259-280.

14. Bryant, S., \& Hunton, J. (2000). The use of technology in the delivery of instruction: Implications for accounting educators and education researchers. Issues in Accounting Education 15(1), 129-162.

15. CAUSE. (1993). Reengineering Teaching and Learning in Higher Education: Sheltered Groves, Camelot, Windmills, and Malls, Professional Paper Series \# 10, edited by R. Heterick, Jr. Boulder, CO: CAUSE.

16. Dede, C. (1992). Education in the twenty-first century. ANNALS, AAPSS, 522, 104-115.

17. Evans, P. (1998). A self-learning project with undergraduate accountancy students using videos and computer technology. Issues in Accounting Education, 3, 729-746.

18. Fetters, M., McKenzie, J., \& Callaghan, D. (1986). Does the computer hinder accounting education? An analysis of some empirical data. Issues in Accounting Education, spring, 76-85. 
19. Gagné, R., Briggs, L., \& Wager, W. (1992). Principles of Instructional Design. Fort Worth: Harcourt Brace Jovanovich College Publishers.

20. Gujarathi, M., \& McQuade, R. (1998). Problems and considerations in implementing technology-based solutions to address changes in accounting curricula. Advances in Accounting Education, 1, 1-23.

21. Harrison, A., \& Rainer, K. (1992). An examination of the factor structures and concurrent validities for the computer attitude scale, the computer anxiety rating scale, and the computer self-efficacy scale. Educational and Psychological Measurement, 44, 501-505.

22. Heinssen, R., Glass, C., \& Knight, L. (1987). Assessing computer anxiety: Development and validation of the computer anxiety rating scale. Computers in Human Behavior, 3, 49-59.

23. Institute for Higher Education Policy (IHEP). (1999). What's the Difference? A Review of Contemporary Research on the Effectiveness of Distance Learning in Higher Education. Washington, DC: IHEP.

24. Kachelmeier, S. J., Jones, J. D., \& Keller, J. A. (1992). Evaluating the effectiveness of a computer-intensive learning aid for teaching pension accounting. Issues in Accounting Education, 7 (2), 164-178.

25. Landry, R. M., Rogers, R. L., \& Harrell, H. W. (1996). Computer usage and psychological type characteristics in accounting students. Journal of Accounting and Computers, spring, http://www. Thomson. com/swcp/acct/jac/jac12/jac12_article4. html.

26. Liu, M., Reed, M., \& Phillips, P. (1992). Teacher education students and computers: Gender, major, prior computer experience, occurrence, and anxiety. Journal of Research on Computing in Education, 24(4), 457-467.

27. Loyd, B., \& Gressard, C. (1984). Reliability and factorial validity of computer attitude scales. Educational and Psychological Measurement, 44, 501-505.

28. Marakas, G., Mun, Y., \& Johnson, R. (1998). The multilevel and multifaceted character of computer selfefficacy: Toward clarification of the construct and an integrative framework for research. Information Systems Research, 9(2), 126-163.

29. Mawhinney, C., Pook, L., \& Shaw, K. (1993). Defining and measuring computer literacy. Procedings of the Twenty First Annual Conference of the International Business School Computing Association, 348-356.

30. McInnes., W., Pyper, D., Van Der Meer, R., \&Wilson, R. (1995). Computer-aided learning in accounting: Educational and managerial perspectives. Accounting Education, 4(4), 319-334.

31. Murphy, C. A., Coover, D., \& Owen, S. V. (1989). Development and validation of the computer selfefficacy scale. Educational and Psychological Measurement, 49, 893-899.

32. Nickell, G. S., and Pinto, J. N. (1986). The computer attitude scale. Computers in Human Behavior, 2, 301306.

33. Oglesbee, T., Bitner, L., \& Wright, G. (1988). Measurement of incremental benefits in computer enhanced instruction. Issues in Accounting Education, fall, 365-377.

34. Parker, J. \&Cunningham, B. (1998). Using an electronic tutorial to enhance students' knowledge of advanced tax accounting. Issues in Accounting Education, (13)2, 395-407.

35. Russell, T. (2000). The "no significant difference phenomenon," http://nova.teleeducation.nb.ca/nosignificantdifference/. (Accessed March 10, 2001.)

36. Siegel, G., \& Sorensen, J. (1994). What Corporate America Wants in Entry-Level Accountants. New York, NY: The Gary Siegel Organization, Inc.

37. Stahlke, H. \& Nyce, J. (1996). Reengineering higher education: Reinventing teaching and learning. CAUSE/EFFECT, winter, pp. 44-51.

38. Stone, D., Arunachalam, V., \& Chandler, J. (1996). An empirical investigation of knowledge, skill, selfefficacy and computer anxiety in accounting education. Issues in Accounting Education. 11(2), 345-376.

39. Teaching and Curriculum Section, American Accounting Association. (1993). Report of the 1992-93 Outcomes Assessment Committee. Sarasota, FL: American Accounting Association.

40. Thompson, A., Simonson, M., \& Hargrave, C. (1992). Educational Technology: A Review of the Research. Washington, D. C.: Association for Educational Communications and Technology.

41. Twigg, C., \& Miloff, M. (1998). The global learning infrastructure. In D. Tapscott, A. Lowy, \& D. Ticoll (Eds), Blueprint to the Digital Economy (pp. 179-201). New York, NY: McGraw-Hill.

42. Williams, J. R., Herring III, H. C., Scheiner, J. H., \& Tiller, M. G. (1988). Framework for the Development of Accounting Education Research, Accounting Education Series, Vol. 9. Sarasota, FL: American Account- 
ing Association.

\footnotetext{
${ }^{1}$ Any new instruments developed in future research will be available from that author's web site an http://www.rrtidd.com.

${ }^{2}$ Additional summary statistics are available from the lead author by request.
}

Notes 